\title{
O cotidiano da imprensa e a imprensa no cotidiano. Surgimento e consolidação de espaços públicos na Vila de Valença no século XIX
}

\section{The daily life press and the press in everyday life. Emergence and consolidation of public spaces in Valenca Village in the nineteenth century}

\author{
Antonio Carlos da Silva \\ Universidade do Estado do Rio de Janeiro \\ antoniovoz@yahoo.com.br
}

\begin{abstract}
Resumo: O presente trabalho tem por objetivo apresentar a análise e os resultados parciais de nossa pesquisa sobre o papel da imprensa no Vale do Paraíba Fluminense, no século XIX, mais especificamente na cidade de Valença. Nossa proposta não se limita a estudar esse meio de comunicação apenas como transmissor de informações, mas pretende analisar como os periódicos faziam parte do cotidiano político da cidade e como estes influenciavam e eram influenciados pela cultura política local. Acreditamos na relevância historiográfica deste trabalho por se tratar de uma análise de conjunto de fontes inéditas ou pouco utilizadas até o momento.
\end{abstract}

Palavras-chave: Império do Brasil; Valença; Imprensa.

Abstract: This paper aims to present an analysis and partial results of our research on the role of the press in the Paraíba Fluminense Valley in the nineteenth century, more specifically in the city of Valença. Our proposal is not limited to studying this means of communication only as transmitter of information, but want to examine the periodic were part of the city's political daily life and how they influenced and were influenced by the local political culture. We believe the historiographical relevance of this work because it is a comprehensive analysis of unpublished sources or little used so far.

Keywords: Empire of Brazil; Valença; Press. 
O Vale do Paraíba tem sido alvo de estudos desde a década de 1940. Durante considerável espaço de tempo a historiografia privilegiou a interface econômica para entender o processo de nascimento do Vale e sua consolidação como principal polo econômico e escravista do Império do Brasil. Segundo Rafael Marquese, ${ }^{1}$ existia, naquela época, uma preocupação historiográfica em demonstrar como o café se transformou em uma alternativa econômica para abastecer o mercado mundial que sofreu com a revolução escrava de São Domingo (1791-1804) e o desenvolvimento industrial europeu. Segundo esses trabalhos, o Vale do Paraíba nasceu como uma consequência natural da crise mineradora em Minas Gerais e das condições favoráveis ao plantio (terras virgens, solo fértil, clima, altitude e proximidade com os portos litorâneos) e, por fim, da demanda no mercado mundial. ${ }^{2}$ Esses estudos criaram o que Marquese chamou de "paradigma dependentista", 3 que se configura na análise do Vale do Paraíba e sua formação baseado no modelo escravista colonial que se voltava para a geração de "riquezas no centro da economia mundial capitalista". 4

A partir do final da década de 1980, verifica-se um esforço para rever esse modelo. O principal argumento era a fragilidade do modelo de ligação com o passado colonial mineiro. Isso começou a ser questionado a partir da constatação de que os estoques de escravos não vinham de Minas Gerais. Tal constatação fez com que os historiadores voltassem seus esforços para entender a ligação econômica do Vale do Paraíba com a estrutura imperial através da dinâmica da sociedade que se constituiu naquele momento. Como exemplo desse esforço, encontramos João Fragoso ${ }^{5}$ e Manolo Florentino ${ }^{6}$. Esses estudos dão conta de entender a relação comercial existente na praça do Rio de Janeiro, do final do século XVIII até meados do século XIX. Para isso, eles analisaram a acumulação de capital nas mãos dos grandes comerciantes do Rio de Janeiro e como os mesmos reinvestiam seu dinheiro na construção de um modelo “arcaico" baseado na posse de terras e escravos como símbolo de distinção social. Segundo Marquese, a interpretação de Fragoso também apresenta alguns problemas, pois, para ele, não é possível compreender "o processo de montagem da cafeicultura escravista brasileira sem remeter a processos globais mais amplos, examinando suas interconexões com as condições locais". 7

A proposta de análise de Marquese pretende estudar a articulação entre as necessidades do mercado internacional e os interesses locais. Segundo ele, o quadro local deve ser entendido através da composição regional da terra, do trabalho e capital e das relações políticas exercidas entre os fazendeiros, trabalhadores escravizados e o Estado nacional. ${ }^{8}$ Marquese apresenta em seu texto um conjunto substancial de informações que dão conta da relação entre a produção escravista do Vale do Paraíba e sua consolidação no mercado internacional. Entretanto, deixa uma lacuna quando não demonstra, de forma

\footnotetext{
${ }^{1}$ MARQUESE, Rafael Bivar. O Vale do Paraíba escravista e a formação do mercado mundial. In: GRINBERG, Keila e SALLES, Ricardo (Orgs.). O Brasil imperial. v. 2. Rio de Janeiro: Civilização Brasileira, 2010.

${ }^{2}$ Sobre esses estudos citamos: PRADO JR. Caio. História Econômica do Brasil. São Paulo: Brasiliense, 1945; STEIN, Stanley J. Vassouras: Um município Brasileiro do café, 1850-1900. Rio de Janeiro: Nova Fronteira, 1990; FURTADO, Celso. Formação Econômica do Brasil. São Paulo: Cia. Editora Nacional, 1974; COSTA, Emilia Viotti da. Da Senzala à Colônia. São Paulo: Brasiliense, 1989.

${ }^{3}$ MARQUESE, Rafael Bivar. Op. cit., p. 343.

4 Idem.

5 FRAGOSO, João Luis Ribeiro. Comerciantes, fazendeiros e forma de acumulação em uma economia escravista colonial: Rio de Janeiro, 1790-1888. Tese (Doutorado em História) - ICHF/UFF, Niterói: 1990 e FRAGOSO, João Luis Ribeiro. Homens de grossa ventura: acumulação e hierarquia na praça mercantil do Rio de Janeiro (1790-1830). Rio de Janeiro: Arquivo Nacional, 1992.

${ }^{6}$ FLORENTINO, Manolo. O arcaismo como projeto. Mercado atlântico, sociedade agrária e elite mercantil em uma economia colonial tardia. Rio de Janeiro (1790-1840). Rio de Janeiro: Civilização Brasileira, 2001.

${ }^{7}$ MARQUESE, Rafael Bivar. Op. cit., p. 344.

${ }^{8}$ Idem.
} 
mais substancial, as relações políticas e sociais existentes no Vale, fundamentais, segundo sua própria argumentação, para entender o Vale do Paraíba dentro do cenário nacional e mundial.

Recentemente, Ricardo Salles ${ }^{9}$ se lançou ao desafio de fazer um panorama do Vale do Paraíba analisando principalmente a cidade de Vassouras. Seu foco foi entender como as principais famílias da região se articulavam em torno da questão da escravidão. Para isso, o autor fez um tratamento demográfico-quantitativo dos dados levantados, em 729 inventários (1821-1880). Para nós, essa obra vem reforçar a teoria da "ideologia saquarema" proposta por seu antigo orientador, Ilmar de Mattos, ${ }^{10}$ na década de 1980. Segundo eles, havia um projeto de poder no qual os principais cafeicultores do Vale direcionavam os interesses do país por meio de parentes e aliados que ocupavam altos cargos na administração imperial. Para isso, Salles utiliza o conceito de intelectual orgânico de Antonio Gramsci. A questão da escravidão ganhou ainda mais força nos debates políticos a partir da década de 1850, por ocasião da Lei de Terras e da Lei Eusébio de Queirós. Para Salles, esses dois eventos modificaram as relações entre os grandes proprietários de terras e o Império do Brasil, uma vez que possuíam vultosos investimentos na mão de obra escrava.

A cidade de Vassouras tem ocupado lugar privilegiado nas pesquisas, nos últimos anos, e atribuímos isso a fatores como a maior acessibilidade às fontes. ${ }^{11}$ As pesquisas sobre o Vale do Paraíba também têm se beneficiado de estudos desenvolvidos em programas de pós-graduação em História. Com o avanço desses programas, a cidade de Valença passou a ser estudada com maior detalhe. Destacamos os trabalhos de Elisa Amorim da Costa, ${ }^{12}$ Marcelo Sant'Ana Lemos, ${ }^{13}$ Argemiro Eloy Gurgel, ${ }^{14}$ Sidney Pereira da Silva, ${ }^{15}$ Rosilene Maria Mariosa ${ }^{16}$ e Antonio Carlos da Silva. ${ }^{17}$

O mais recente trabalho é o de Raimundo César de O. Mattos. ${ }^{18}$ Sua proposta foi bem original e seguiu no contrafluxo da historiografia, apresentando o português Manoel Antônio Esteves, como homem de negócios diferente dos demais fazendeiros locais. Mattos analisou as correspondências enviadas e recebidas por Manoel Esteves. Pôde observar as estratégias de sociabilidade construídas por um homem que chegou ao Vale do Paraíba como caixeiro e se tornou um dos fazendeiros mais influentes da região. Manoel Antônio Esteves foi um personagem que transitou primeiramente em Vassouras e depois se estabeleceu em Valença, onde construiu sua vida e se casou com Maria Francisca Esteves, filha de um dos primeiros sesmeiros de Valença, Francisco Martins Pimentel. Esse casamento, conforme demonstrou

\footnotetext{
${ }^{9}$ SALLES, Ricardo H. E o Vale era o escravo. Vassouras, século XIX. Senhores e escravos no coração do Império. Rio de Janeiro: Civilização Brasileira, 2008.

${ }_{10}$ MATTOS, Ilmar R. de. O tempo saquarema. São Paulo: Hucitec, 1987.

${ }^{11}$ Desde o final da década de 1990, a Universidade Severino Sombra, localizada em Vassouras, mantém convênio com o Tribunal de Justiça do Estado do Rio de Janeiro que prevê a guarda de diversos processos referentes àquela cidade. Para cumprir tal acordo, a instituição criou e mantém o Centro de Documentação Histórica que cuida, organiza e disponibiliza os processos para pesquisa. Além desse arquivo, existe na cidade o Arquivo da Câmara Municipal de Vassouras e o da Paróquia de Nossa Senhora da Conceição.

${ }^{12}$ COSTA, Elisa Amorim da. Irmandade da Santa Casa de Misericórdia de Valença (1838-1889). Dissertação (Mestrado em História Social) - PPGHIS/USS, Vassouras, 1997.

${ }^{13}$ LEMOS, Marcelo Sant'Ana. O índio virou pó de café? A resistência dos índios Coroados de Valença frente à expansão cafeeira no Vale do Paraíba (1788 - 1836). Dissertação (Mestrado em História) - PPGH/UERJ, 2004.

14 GURGEL, Argemiro Eloy Gurgel. A Lei de 31 de março de 1831 e as ações de liberdade em Valença (1870 a 1888). Dissertação (Mestrado em História Social) - PPGHIS IFCS/UFRJ, Rio de Janeiro, 2004.

${ }_{15}$ SILVA, Pereira da Silva. As relações sócio-parentais entre escravos: o batismo de escravos em Valença, província do Rio de Janeiro (1823-1885). Dissertação (Mestrado em História Social) Vassouras: PPGHIS/USS, 2005.

${ }^{16}$ MARIOSA, Rosilene Maria. Tratamento e doenças de escravos da Fazenda Santo Antonio do Paiol: 1850-1888.

Dissertação (Mestrado em História) - PPGHIS/USS, 2006.

17 SILVA, Antonio Carlos da. A boa sociedade valenciana do século XIX: redes de sociabilidade (1829-1868). Dissertação (Mestrado em História) - PPGHIS/USS, Vassouras, 2010.

${ }^{18}$ MATTOS, Raimundo César de Oliveira. Manoel Antônio Esteves - Um capitalista esquecido no Vale (1850-1879).

Tese (Doutorado) - PPGH/UERJ, Rio de Janeiro, 2012.
} 

Mattos, possibilitou que o Sr. Esteves adentrasse na boa sociedade local, vivenciando uma metamorfose de mascate a fazendeiro e comissário de café. Outro ponto que deve ser ressaltado é que, ao contrário de Rafael Marquese e Ricardo Salles, Raimundo Mattos não trata as vilas de Valença e Vassouras como homogêneas, mas sim com bastante distinção no campo político. Para isso, ele buscou explicações no processo de formação das duas vilas. Enquanto Vassouras nasceu de um projeto político das famílias Teixeira Leite e Correia e Castro, Valença se formou em torno de uma elite rural extremamente heterogênea, fato que descemos mais fundo em nossa pesquisa.

Anteriormente os poucos estudos que existiam sobre o local eram produzidos por memorialistas locais com a finalidade de "preservar" a memória da cidade. Os dois principais memorialistas foram: Luiz Damasceno $^{19}$ e José Leoni lório, ${ }^{20}$ que publicaram suas obras nas décadas de 1920 e 1950 respectivamente. No ano de 2004, Rogério da Silva $\operatorname{Tjader}^{21}$ se propôs a acrescentar algumas informações sobre a história local principalmente com sua biografia do Visconde do Rio Preto, obra esta, que a exemplo dos seus predecessores é bem documentada, mas narra e fortalece o mito dos grandes personagens locais.

Um trabalho mais recente é o de Gustavo Abruzzini de Barros ${ }^{22}$ que se apresenta como um inventário da imprensa valenciana desde seus primórdios no século XIX até os jornais publicados na década de 1990. A relevância de tal obra se apresenta pelo esforço do autor em pesquisar tamanho volume de periódicos e dar ao público um panorama geral da imprensa na cidade de Valença. A historiografia sobre Valença avançou significativamente nos últimos anos, entretanto, percebemos que os memorialistas e os pesquisadores acadêmicos não privilegiaram a imprensa valenciana como objeto passível de crítica e análise histórica.

Entendemos a imprensa não apenas como um simples registro do que aconteceu, mas como uma "força ativa na história", assim como Robert Darnton ${ }^{23}$ procurou fazer ao estudar o papel da imprensa na França, no final do século XVIII. Para Darnton, a imprensa exerceu um papel fundamental no processo revolucionário francês que levou ao fim do Antigo Regime.

Dentro do Império do Brasil, a região do Vale do Paraíba do Sul acabou tornando-se estratégica economicamente por conta da produção de café que ali foi instalada e se proliferou, proporcionando o surgimento de uma nobreza rural que, durante grande parte do império, serviu de sustentáculo político e econômico nacional.

Nosso trabalho tem como recorte espacial a cidade de Valença, na província do Rio de Janeiro, que tem origens no final do século XVIII, quando era habitada pelos índios Coroados. Nessa época, a Coroa portuguesa resolveu incentivar o crescimento da região com a doação de sesmarias. A margem direita do Rio Paraíba do Sul já havia sido dividida, e era a vez da margem esquerda que compreendia os atuais municípios de Valença, Rio das Flores, parte de Barra do Piraí e Paraíba do Sul. Em 1803, foi fundada a Aldeia de Nossa Senhora da Glória de Valença e, em 1823, foi elevada à condição de Vila, sendo que o

\footnotetext{
${ }^{19}$ FERREIRA, Luiz Damasceno. História de Valença. Valença: Valença, 1924.

20 IÓRIO, José Leoni. Valença de Ontem e de Hoje. Subsídios para pesquisa. 1789-1952. 2. e. Valença: Jorge lório. 2013.

${ }^{21}$ TJADER, Rogério da Silva. Visconde do Rio Preto, Sua Vida, Sua Obra, o Esplendor de Valença. Valença: PC Duboc Ltda., 2004.

22 BARROS, Gustavo Abruzzini de. Imprensa Valenciana. Do provincianismo da era de barões e coronéis ao engatinhar do profissionalismo do século XXI. Valença: Jornal Local, 2012.

${ }^{23}$ Cf. DARNTON, Robert. Introdução. In: DARNTON, Robert e ROCHE, Daniel (Orgs.). Revolução impressa: a imprensa na França, 1775-1800. Trad. Marcos M. Jordan. São Paulo: Ed.USP, 1996. p. 15.
} 
pelourinho somente foi erguido em 1826. No ano de 1857, no auge da produção cafeeira, Valença juntamente com Vassouras foram elevadas à categoria de cidade. ${ }^{24}$

Com sua economia baseada na escravidão e no plantio de café, a cidade de Valença abrigou alguns dos políticos mais influentes do Império do Brasil, como o marquês de Baependy, ministro de D. Pedro I, e seu filho, o conde de Baependy, ${ }^{25}$ vereador, deputado, presidente das províncias do Rio de Janeiro e Pernambuco, além de presidente do Senado. Além deles, podemos citar o visconde do Rio Preto, sócio do conde de Bonfim, Joaquim Saldanha Marinho, que chegou a ser vereador na cidade, e o barão de Guaraciaba, único barão negro do Império, entre muitas outras personalidades.

Valença contou com um número considerável de periódicos a partir de 1832. Esses jornais apresentam um conteúdo rico sobre os modos, costumes e as relações político-sociais da cidade. Utilizaremos, no presente estudo, quatro periódicos locais, a saber: O Valenciano (1832-1833), O Merrimac (1862-1863), O Valenciano (1864-1865) e A Phenix (1867). Dois motivos nos levaram a escolher esses jornais, sendo o primeiro deles a acessibilidade, pois encontramos a coleção completa do primeiro jornal no setor de Obras Raras da Biblioteca Nacional, ao passo que os outros três jornais fazem parte de uma rara coleção preservada e digitalizada da Fazenda Santo Antonio do Paiol e que, até o momento, não temos conhecimento da existência de outros exemplares. O segundo fator foi a delimitação espacial, pois estamos utilizando somente os jornais da Freguesia de Nossa Senhora da Glória, onde estava localizado o centro administrativo do município. Sendo assim, nossas fontes nos levam a outro recorte, o temporal, que tem como marcos os anos de 1832, quando foi publicada a primeira edição de $O$ Valenciano e 1867, ano da última edição de $A$ Phenix.

A maioria das pesquisas desenvolvidas sobre o Vale do Paraíba utilizou atas de instituições, inventários post-mortem, relatórios governamentais e até relatos de viajantes. A imprensa da região ainda não ocupou espaço privilegiado nos estudos até agora. Atribuímos isso ao fato da imprensa só ter se desenvolvido, na maior parte da região, a partir da década de 1880, com exceção das vilas de Valença e Resende, ${ }^{26}$ que possuíram periódicos já na década de 1830, com breve atividade - uma pausa de aproximadamente trinta anos e retorno na década de 1860.

Nossos objetivos são: compreender como a imprensa fazia parte do cotidiano político da cidade de Valença no século XIX e como ela se transformou em um espaço público de sociabilidade. Pretendemos demonstrar quais eram os agentes por trás da imprensa valenciana, quais estratégias utilizavam para unir os fazendeiros, proprietários e comerciantes ${ }^{27}$ locais em torno de interesses em comum. Demonstraremos qual a importância da imprensa na consolidação de algumas famílias no poder. Para isso, nos articulamos como Marialva Barbosa ao propor que a constituição da imprensa no Brasil se relaciona com a consolidação de uma mentalidade abstrata, capaz de conferir "valor efetivo a algo imaterial com ideias que circulam sob forma de jornal". ${ }^{28}$

\footnotetext{
${ }^{24}$ Cf. FERREIRA, Luiz Damasceno. História de Valença. Valença: Valença, 1924.

${ }^{25}$ Brás Carneiro Nogueira da Costa e Gama (1812-1887) foi vereador em Valença entre 1833-1836, 1837-1840, 18491852, 1853-1856. Ocupou o cargo de presidente da província de Pernambuco em 1868. Foi deputado provincial de 1850 a 1864 e deputado geral pelo Rio de Janeiro entre 1869 e 1872 . Foi escolhido para o Senado em 1872 onde ficou até 1887. Foi presidente da Assembleia Provincial, Câmara dos Deputados e do Senado do Império por várias oportunidades.

${ }^{26}$ O Gênio Brasileiro (1831-1833) foi o primeiro jornal do Vale do Paraíba editado na Vila de Resende pelo padre José Marques de Motta. Posteriormente, surgiu o Echo Costitucional (1837-1843). Houve um hiato de 21 anos até que, em 1864, surgiu O Astro Resendense (1864-1873).

27 O Almanak administrativo, mercantil, e industrial do Rio de Janeiro classificava como proprietários os donos de imóveis nas cidades.

${ }_{28}^{28}$ BARBOSA, Marialva. História Cultural da Imprensa: Brasil, 1800-1900. Rio de Janeiro: Mauad X, 2010. p. 21.
} 
O surgimento e a consolidação da imprensa no Brasil estão diretamente ligados ao nascimento do Estado brasileiro. Marco Morel $^{29}$ alerta para o perigo de olharmos para esse processo com uma visão simplista de uma sociedade composta por "um punhado de senhores e uma multidão de escravos em oposição a uma metrópole que controlava tudo". ${ }^{30}$ Segundo ele, muitos espaços foram criados para possibilitar a circulação de ideias, estabelecendo-se assim um espaço público. A noção de espaços públicos

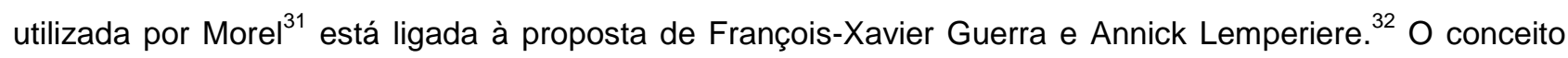
apresentado por eles é capaz de nos mostrar um elo mais forte que apenas o espaço geográfico de circulação daqueles jornais. Guerra e Lemperiere defendem o conceito de "espaço público" em oposição ao conceito de "esfera pública" utilizado por Jürgen Habermas, pois, segundo eles, a proposta habermasiana não dá conta da pluralidade que é o mundo ibero-americano.

Diante disso, passamos a entender os jornais valencianos como espaços públicos de sociabilidade como fez Marco Morel $^{33}$ ao estudar a cidade do Rio de Janeiro entre 1820 e 1840 . O autor dá ênfase à elaboração de novos e diversos espaços públicos: o nascimento do homem de letras e seus congêneres - 0 publicista, o gazeteiro, o redator, a nobreza letrada; as intersecções entre as elites, os homens de letras e os homens que atuam na esfera política - eleitores, elegíveis e eleitos; o novo vocabulário em voga e as disputas pelo domínio da palavra pública; a fundação da noção de opinião pública; a noção de sociabilidade entremeada com a política.

Morel $^{34}$ sugere que a análise da imprensa esteja ligada ao entendimento da linguagem utilizada. Para ele, as expressões impressas e orais estão marcadas por uma clivagem social, ou seja, é possível perceber as separações sociais criadas no seio de uma sociedade. ${ }^{35}$ Entendemos que os grupos sociais e indivíduos dão sentido ao seu mundo através de práticas produzidas por representações. Essas acontecem quando há uma incorporação da estrutura social pelos indivíduos. Por outro lado, cada indivíduo socialmente organizado constrói uma representação de si a partir de gestos, de um estilo de vida, de uma existência. A realidade social é constituída pela forma como cada grupo ou indivíduo cria sua representação de si, bem como seu reconhecimento ou não por parte de outros grupos. ${ }^{36}$

O primeiro jornal que surgiu na cidade foi $O$ Valenciano, em 1832, de propriedade da Sociedade Defensora da Liberdade e Independência Nacional da Villa de Valença, fundada e presidida por Brás Carneiro da Costa e Gama, o visconde de Baependy, logo após a abdicação de D. Pedro I, e composta por vários fazendeiros e políticos locais que temiam a independência do Brasil. O jornal traz, logo na primeira edição, como epígrafe, um trecho do estatuto social daquela sociedade:

Seus fins serão: sustentar por todos os meios legais a Liberdade, e Independência Nacional, auxiliando a ação das Autoridades Publicas, todas as vezes, que se faça mister a bem da ordem, e tranqüilidade Publica, usando do direito de petição para as medidas, que não estiverem ao seu alcance, e ainda quando se julguem necessárias

\footnotetext{
${ }^{29}$ MOREL, Marco. Os primeiros passos da palavra impressa. In: MARTINS, Ana Luiza \& LUCA, Tânia Regina de (Orgs). História da Imprensa no Brasil. São Paulo: Contexto, 2008.

30 Ibidem. p. 26.

${ }^{31}$ MOREL, Marco. As transformações dos espaços públicos. Imprensa, atores políticos e sociabilidades na cidade imperial. 1820-1840. São Paulo: Hucitec, 2005.

32 GUERRA, François-Xavier. LEMPÉRIĖRE, Annick et al. Los espacios públicos en Iberoamérica. Ambigüedades y problemas. Siglos XVIII-XIX. Cidade do México: Fondo de Cultura Económica, 1998.

${ }^{33}$ MOREL, Marco Morel, Op. cit.

${ }^{34}$ MOREL, Marco. Palavras Além das Letras: Apontamentos sobre imprensa e oralidade na primeira metade do século XIX. Rio de Janeiro: Acervo. Arquivo Nacional, v. 23, n. 1. pp. 63-80, (2010).

35 Ibidem. p. 67.

${ }^{36}$ CHARTIER, Roger. À beira da falésia: a história entre certezas e inquietude. Trad. Patrícia Chittoni Ramos. Porto Alegre: Editora da Universidade, UFRGS, 2002. p. 66.
} 
medidas maiores, reclamando-as somente por meios legais: promover a Agricultura principal riqueza d'este Termo; a Instrução publica, principal fundamento do Edifício Social; a Industria, e Artes, bases da Felicidade Nacional. ${ }^{37}$

Podemos observar que essa instituição surgida em Valença seguiu os mesmos fundamentos de sua congênere do Rio de Janeiro, da qual se originou. Lúcia Guimarães ${ }^{38}$ aponta que o objetivo daquela sociedade era a manutenção da ordem, a moderação e o respeito às leis. Essas sociedades buscavam a manutenção de instituições ora ameaçadas pela abdicação de D. Pedro I. O Valenciano surgiu como plataforma de atuação da Sociedade Defensora da Villa de Valença, mas por motivos que ainda estamos estudando, encerrou suas atividades em 1833, somando um total de cinquenta edições.

A partir de 1862, outro jornal passou a circular na cidade: O Merrimac. Editado por um grupo de sócios, entre os quais podemos citar João Rufino Furtado de Mendonça, um político local descendente de uma família tradicional na área jurídica e aliado do visconde do Rio Preto. Era o dono da tipografia que produzia a publicação. Sua marca registrada sempre foi a parcialidade política, embora afirmasse 0 contrário. Em 1864, João Rufino assumiu totalmente o controle do jornal e o transformou em O Valenciano, ocupando o posto de redator. Esse jornal durou até 1865, quando, por conta de um processo judicial, deixou de ser impresso. Com um nome sugestivo, em 1867, surgiu $A$ Phenix, uma alusão ao pássaro mitológico que ressurge das cinzas. Certamente o nome não poderia ser mais apropriado uma vez que era o retorno de João Rufino à imprensa.

Para Roger Chartier "um texto existe apenas porque há um leitor para Ihe atribuir um significado". ${ }^{39}$ Os leitores compartilham dispositivos, comportamentos e atitudes, significados culturais e representações sociais. Essas leituras se realizam em um espaço histórico e são plurais como práticas de invenção de sentidos. ${ }^{40}$ Compreender essa relação "implica reconhecer o vínculo essencial entre o texto em sua materialidade, que suporta os textos, e as práticas de apropriação, que são as leituras"41 $\mathrm{O}$ jornal é, então muito mais do que apenas uma folha semanal distribuídas aos fazendeiros. É um espaço de apropriação de significados. Essa apropriação está ligada à construção de um sentido a partir da leitura frente aos discursos produzidos e direcionados pelos elementos inseridos nas páginas que compõem o texto.

Verificamos que entre 1834 e 1862 houve uma lacuna de quase trinta anos sem que houvesse a edição de jornais em Valença. Isso não significa dizer que não havia circulação de jornais e ideias na cidade. Pudemos perceber que, durante esses anos, os proprietários rurais, comerciantes e outros personagens locais se valeram de jornais editados no Rio de Janeiro para expor opiniões, fazer denúncias e elogios a seus pares, além de divulgar suas ações políticas e fortalecer seus laços de sociabilidade. Entre esses jornais destacamos o Correio Mercantil, Correio da Tarde e o Diário do Rio de Janeiro que também utilizamos em nosso trabalho. Inicialmente acreditávamos que, por haver um distanciamento temporal tão grande, não havia uma conexão entre O Valenciano, publicado em 1832, e O Merrimac, lançado em 1862. Ao longo da pesquisa, pudemos perceber que tais empreendimentos estavam no centro da manutenção dos interesses dos proprietários rurais da localidade que tinham como liderança a família Nogueira da Gama.

\footnotetext{
${ }^{37}$ O Valenciano. Ano I, n. 1, 26/05/1832. Microfilme PR-SOR 00495 BN.

38 GUIMARÃES, Lúcia Maria Paschoal. Em nome da ordem e da moderação: a trajetória da Sociedade Defensora da Liberdade e da Independência Nacional. Dissertação (Mestrado) - UFRJ, Rio de Janeiro, 1990, p. 15.

${ }^{39}$ CHARTIER, Roger. A ordem dos livros. Lisboa: Vega: Passagens, 1997, p. 12.

40 Idem.

${ }^{41}$ CHARTIER, Roger. Cultura escrita, literatura e história: conversas de Roger Chartier com Carlos Aguirre Anaya, Jesús Anaya Rosique, Daniel Goldin e Antonio Saborit. Trad. Ernani Rosa. Porto Alegre: ArtMed, 2001, p. 29.
} 
Nesse momento, podemos afirmar que $O$ Valenciano estava no centro da consolidação e do estabelecimento de uma ordem senhorial na cidade de Valença. Após a conquista de uma estabilidade política, econômica e social não havia a necessidade de edição de jornais na cidade. No final dos anos 1830 e durante a década de 1840, essa ordem foi mantida, e os jornais da Corte serviam para divulgar alguns interesses do grupo, acompanhamento das eleições, elogios mútuos etc. Todavia, o que se viu na cidade, na década de 1850 , foi uma perturbação da ordem senhorial estabelecida até então. De um lado ficaram os liberais sob o comando de Joaquim Saldanha Marinho; e do outro, o conde de Baependy e o visconde de Ipiabas à frente dos conservadores. Tal disputa fica muito clara na fala de João Rufino, por ocasião da morte do visconde do Rio Preto, principal elo de articulação entre os dois lados:

Foi no memorável dia 7 de setembro de 1868, seu aniversário, que esse distinto cidadão, rodeado de sua família e de seus amigos mais devotados deu a alma ao Credor. Nessa ocasião Srs., em que o povo deste Município, dividido em duas parcialidades políticas inconciliáveis, disputavam ambas em todas as paróquias a gloria de o trazerem pela terceira vez a presidência desta Câmara; para com ele desapareciam as paixões partidárias para só sobressair o espírito de reconhecimento. $^{42}$

Havia um forte embate entre os dois lados, mas a desunião não favorecia nenhum deles. O café, principal produto dos fazendeiros locais, estava perdendo espaço no mercado por conta dos altos custos de transporte, por exemplo. Uma solução seria a construção de um ramal que ligasse Valença à Estrada de Ferro D. Pedro II, que passaria no Arraial de Desengano, não por acaso, às portas da Fazenda Santa Mônica, de propriedade do marquês de Baependy. Tal empreitada requeria a união das duas partes e, com seus jornais, dois agentes foram importantes nesse processo, o visconde do Rio Preto e João Rufino Furtado de Mendonça:

\begin{abstract}
Questão importantíssima de que nos ocupamos em nosso artigo anterior, está sendo agitada em todos os círculos desta cidade. A ideia generosa de ligar os municípios de Valença, do Rio Preto e circunvizinhos, ao grande mercado do Rio de Janeiro por via férrea, não podia, com efeito, deixar de ser acolhida por todos os nossos concidadãos.

Homens de reconhecida experiência aos quais não se pode opor, a objeção de leviandade, acham-se cooperando eficazmente para que os habitantes deste município reúnam seus esforços combinados para interessante fim.

Nomearemos, entre outros, e como dignos do reconhecimento público por este motivo, os Srs. Herculano Furtado e Mendonça Antonio Carlos, Araújo Leite, Araújo e Silva, Drs. Lima, Tavares Bastos, Fernandes e Guilherme, Negreiros Américo Ferreira, e Fonseca, aos quais todos temos ouvido aderir da maneira mais formal a praticabilidade do ramal de Valença. ${ }^{43}$
\end{abstract}

Assim como em 1832 os jornais publicados por João Rufino seriam utilizados na consolidação de ordem senhorial baseada na conquista da opinião pública:

Aproxima-se a nova quadra eleitoral, sim, pouco mais de sessenta dias falta para a eleição primária e já ao longe se houve o som do clarim, que voz convida a exercer o sagrado direito que a Constituição vos concede.

Já uma reunião de um dos partidos, consta-se ter feito, para se tratar da eleição, pois bem: preparai-vos, marchai no memorável dia sete de Setembro à Matriz desta cidade, lançai vossa cédula na urna, mas escolhei, escolhei bem e conscientemente os nomes que devem compor esta lista:

(...)

\footnotetext{
42 MENDONÇA, João Rufino Furtado de. Relatório de Gestão da Câmara Municipal de Valença, 1869. CD $011 \mathrm{CDH} / \mathrm{CESVA}$.

${ }^{43}$ O Merrimac. Ano II n. I, 1\%/01/1863.
} 
A contenda eleitoral está finda, etc, etc... Enfim o povo valenciano, livre correu as ruas com seus sufrágios.

(...)

Eis por fim chegada a nova época de vossa soberania, exercei vossos direitos com dignidade abraçai a quem de vós cuidou, desprezai a quem vos desprezou. ${ }^{44}$

Verificamos que os jornais estão no cerne de uma cultura política local, agindo com interface das relações criadas e fortalecidas por fazendeiros e políticos da Vila de Valença. Assim como Serge Berstein, ${ }^{45}$ percebemos que a Cultura Política surgiu como a resposta mais satisfatória para entender os comportamentos políticos no decorrer da história. Para nós, ela é uma espécie de código e um conjunto de referência formalizado no seio de um partido ou, mais largamente, difundido no seio de uma família ou de uma tradição política, conforme faziam os jornais estudados.

Concluindo, até o presente momento, pudemos constatar a influência política e social de algumas famílias na Vila de Valença como: Nogueira da Gama, Leite Ribeiro, Pinheiro de Souza, Werneck e Vieira Machado. Tais famílias se utilizavam dos jornais para fortalecimento de seus projetos e para formar uma opinião pública em torno deles. Assim como no Rio de Janeiro, sede da Corte, a palavra escrita desempenhava importante papel também na Vila de Valença, consolidando-se como um espaço público de atuação da "boa sociedade" local.

Antonio Carlos da Silva: Professor no Centro Universitário Geraldo Di Biase, em Volta Redonda, atualmente cursa Doutorado em História na Universidade do Estado do Rio de Janeiro. Suas pesquisas se concentram em estudar a aristocracia rural do médio Vale do Paraíba e sua atuação dentro do Império do Brasil.

\footnotetext{
${ }^{44}$ O Roceiro. A pedido. In: O Valenciano, Ano I, n. 18, 25/06/1864.

45 BERSTEIN, Serge. A cultura política. In: RIOUX, Jean-Pierre \& SIRINELLI, Jean-François. Para uma história cultural. Lisboa: Editorial Estampa, 1998.
} 